\title{
Phaeochromocytomas overexpress insulin transcript and produce insulin
}

\author{
Ivar Følling ${ }^{1,2,3}$, Anna B Wennerstrøm $\mathbb{1 0}^{3}$, Tor J Eide ${ }^{4}$ and Hilde Loge Nilsen ${ }^{2,3}$ \\ 1'Department of Endocrinology, Akershus University Hospital, Lørenskog, Norway \\ ${ }^{2}$ Institute of Clinical Medicine, University of Oslo, Oslo, Norway \\ ${ }^{3}$ Department of Clinical Molecular Biology, University of Oslo and Akershus University Hospital, Lørenskog, Norway \\ ${ }^{4}$ Division of Laboratory Medicine, Department of Pathology, Oslo University Hospital, Oslo, Norway

\begin{abstract}
Introduction: Phaeochromocytomas are tumours originating in the medulla of the adrenal gland. They produce catecholamines, and some tumours also produce ectopic hormones. Two types of glucose imbalances occur in phaeochromocytoma patients, hyperglycaemia and hypoglycaemic attacks. Therefore, we tested whether insulin transcript (INS), insulin, and a hybrid read-through transcript between exons from insulin and insulin-like growth factor 2 (INS-IGF2) were expressed in phaeochromocytomas. Methods: We measured the expression of insulin using immunohistochemistry. The expression of INS-IGF2 was determined by qRT-PCR in formalin-fixed and paraffinembedded tissue from 20 phaeochromocytomas. The expression of INS and INS-IGF2 transcripts was also analysed in 182 phaeochromocytomas and paragangliomas using publicly available datasets in The Cancer Genome Atlas (TCGA) Database. Results: Of 20 phaeochromocytomas, 16 stained positive for insulin. The distribution of positive cells was mostly scattered, with some focal expression indicating clonal expansion. Nineteen tumours expressed high levels of INS and INS-IGF2 transcripts. The expression of the two transcripts corresponded closely. In the TCGA dataset, phaeochromocytoma expresses higher levels of INS and INS-IGF2 transcripts compared to the normal non-tumour adrenal glands. Thus, the expression of INS and INS-IGF2 seems to be a general phenomenon in phaeochromocytoma. Conclusion: Most phaeochromocytomas contain cells that overexpress INS and INS-IGF2 transcripts. Most tumours also display heterogeneous expression of polypeptides immunoreactive to monoclonal anti-insulin antibodies. Clinically this may relate to both hyperglycaemia and hypoglycaemic attacks seen in patients with phaeochromocytoma as well as autocrine tumour growth.
\end{abstract}

Key Words

- phaeochromocytoma

- insulin

- INS-IGF2

- ectopic production

- ectopic transcription

- tumour-induced hypoglycaemia

- tumour-induced hyperglycaemia

- immunohistochemistry

\section{Introduction}

Phaeochromocytomas are tumours originating in the medulla of the adrenal gland. As the normal adrenal medulla, phaeochromocytomas mainly produce catecholamines but a few also produce ectopic hormones. Clinically, the most important ectopic hormone is adrenocorticotropic hormone causing Cushing syndrome that adds to the typical phaeochromocytoma symptoms $(1,2)$.
Staining with anti-insulin was described in five of seven phaeochromocytomas (3).

Other examples of ectopic insulin production are rare. It is found in a few cases with tumours in the cervix, lung, kidney, paraganglioma, and ovary. The evidence for insulin production in these tumours is, for some of them, limited to staining with anti-insulin antibodies $(4,5,6,7)$. https://ec.bioscientifica.com https://doi.org/10.1530/EC-21-0269 (c) 2021 The authors Published by Bioscientifica Ltd

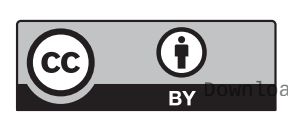

This work is licensed under a Creative Commons Attribution 4.0 International License. 
Other studies, in addition, include in situ hybridisation of insulin mRNA (8), insulin extracted from tumour (9), cultured cells demonstrating insulin production (10), granules similar to those in beta cells $(11,12)$, and/or cure of hypoglycaemia after tumour extirpation $(10,12,13)$. There are also reports of patients with hyperinsulinemic hypoglycaemia without convincing evidence that their extrapancreatic tumour produced the insulin.

Dysregulated ectopic production of insulin and related molecules could cause or contribute to the two kinds of glucose imbalances seen in patients with phaeochromocytoma. First, hyperglycaemia is common, occurring in $21-37 \%$ of the patients and is probably caused by the secreted catecholamines that inhibit insulin secretion and increase insulin resistance (14). In addition, we suggest that insulin-related molecules partly mimicking insulin may block the insulin receptor, and thereby contribute to hyperglycaemia. Secondly, rare cases with hypoglycaemic attacks have been reported in phaeochromocytoma patients $(15,16,17,18)$ but the mechanism is unknown. Hypersecretion of insulin from the tumour may cause hypoglycaemia.

Phaeochromocytomas overexpress insulin-like growth factor 2 transcript (IGF2 transcript) (19) and the translated protein IGF2 (20). The insulin gene and the IGF2 gene are located after each other on chromosome subband 11p15.5 (Fig. 1). These two genes can give rise to read-through hybrid transcripts composed of exons from both genes: the INS-IGF2 transcript 1, a long transcript believed never to be translated into protein as an early stop codon targets it to nonsense-mediated decay, and INS-IGF2 transcript 2, a shorter transcript (Fig. 1) that codes for a 200 amino acid protein.

In this study, we report that most phaeochromocytomas overexpress INS and INS-IGF2 transcripts and insulin.

\section{Methods}

\section{Patients}

We obtained consent from 20 patients with phaeochromocytomas operated consecutively from 2015 to 2017, to retrospectively investigate their tumours. There were an equal number of female and male (10/10) patients with age span 30-70 years (median 57). Two patients had known germline mutation predisposing to phaeochromocytoma; one heterozygote FN1 mutation: c.1527+4_1527+7 del and one heterozygote MAX mutation: exon 3 c.149T $>$ A (Val 50 Asp). Seven patients had hyperglycaemia. Seventeen of the 20 patients were Caucasians. No patients showed evidence of predisposing germline mutations in SDH genes. The hospital recruits unselected phaeochromocytoma patients (Supplementary Table 1 , see section on supplementary materials given at the end of this article). All data in the table are as expected in an average cohort of phaeochromocytoma patients. Consent was given by the Regional Ethics committee (2018/196) and The Data Protection Officer (7_2018).

\section{Tumours}

Neighbouring slices of formalin-fixed paraffin-embedded (FFPE) tissue from the 20 tumours were used for RNA studies and immunochemistry. Tumour diameters were $1.9-9.5 \mathrm{~cm}$ (median $5 \mathrm{~cm}$ ).

\section{Total RNA extraction}

Slices of $10 \mu \mathrm{m}$ were mounted on glass slides and left to dry overnight at room temperature. Macrodissection of tumour tissue was performed to obtain pure tumour tissue cleared of the normal adrenal cortex. Total RNA was extracted

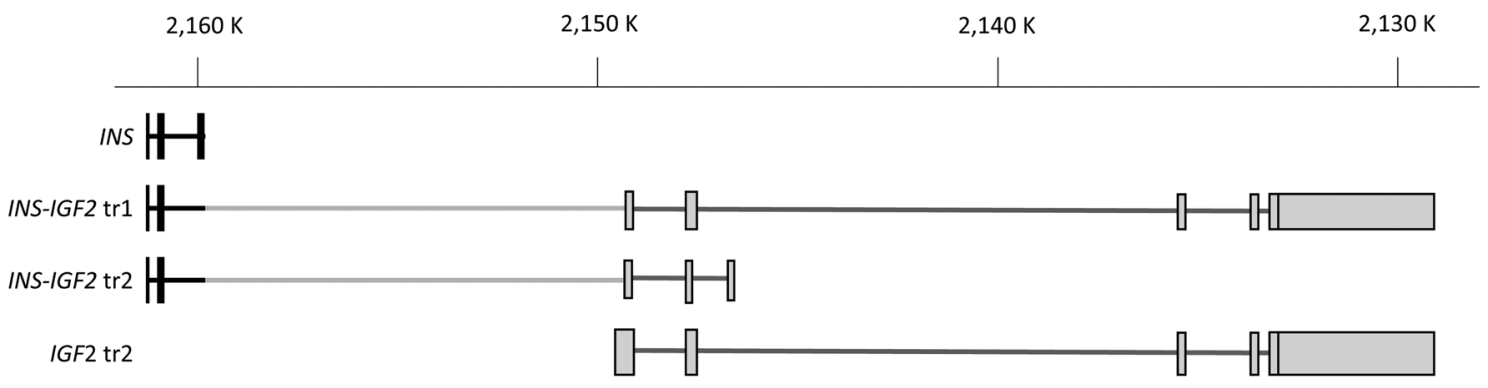

Figure 1

Overview of the transcripts generated from the INS-IGF2 locus on chromosome 11. Starting from the top, the four transcripts shown are the INS transcript, the long INS-IGF2 transcript 1 (noncoding), the short INS-IGF2 transcript 2 (coding), and the IGF2 transcript 2. Exons are depicted as tall boxes and intron as line. Parts annotated as encoded within the insulin gene are shown in black, and the light grey parts designate IGF2 gene origin. The scale above indicates the genomic position.

https://ec.bioscientifica.com https://doi.org/10.1530/EC-21-0269 (c) 2021 The authors Published by Bioscientifica Ltd

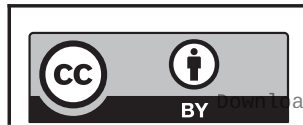

This work is licensed under a Creative Commons Attribution 4.0 International License. ded from Bioscientifica.com at 04/26/2023 09:30:10AM 
using the RNeasy FFPE Kit (Qiagen) as recommended by the manufacturer, and RNA concentration was measured with Qubit RNA BR kit (Invitrogen). RNA quality was measured using Bioanalyzer, and the DV200 values were calculated to be $>85 \%$ for phaeochromocytoma samples and the negative control and 39\% for the positive control. Thus, all samples meet the standard 30\% cut-off.

\section{PCR and quantitative reverse transcriptase PCR (RT-qPCR)}

Expression of insulin transcripts was detected with RT-qPCR. For cDNA synthesis, $300 \mathrm{ng}$ of total RNA was reverse transcribed with SuperScript VI, Random Hexamers, dNTP, RNaseOUT RNase Inhibitor (all from Invitrogen), as recommended by the manufacturer. With cDNA input equivalent to 4 ng total RNA, using Power SYBR Green PCR Master Mix (Applied Biosystems) with primers F: 5'-GAAGCGTGGCATTGTGGAA-3' and R: 5' - GCGTCTAGTTGCAGTAGTTCT-3'. The PCR programme $\left(10 \mathrm{~min}\right.$ at $\left.95^{\circ} \mathrm{C}, 30 / 34 \times\left(15 \mathrm{~s} 95^{\circ} \mathrm{C}, 1 \mathrm{~min} 62^{\circ} \mathrm{C}\right)\right)$ was run on Mastercycler $\times 50$ (Eppendorf, Hamburg, Germany). For the INS-IGF2 transcript 2, we used QuantiTech Primer Assay (Qiagen) using PCR conditions as described for insulin. In all reactions, normal pancreas and normal adrenal gland were used as controls.

PCR products were separated by electrophoresis on 2\% TAE/agarose gels using UltraPure Agarose (Invitrogen). Pictures were acquired and quantified by fluorescence using the Gel-doc XR+ system and ImageLab 5.2.1 software (both from Bio-Rad).

Relative quantification of insulin expression was also performed by qPCR, by comparing the $\mathrm{Ct}$ value from patient samples with $\mathrm{Ct}$ values from a standard curve made from dilutions of the insulin cDNA from the pancreas. The reaction was run in a 384 format on QuantStudio7 (Applied Biosystems), otherwise as described for regular PCR.

\section{Bioinformatics}

Gene expression data from pheochromocytoma and paraganglioma (PCPG) are available through the Cancer Genome Atlas (TCGA) Research Network (https:// www.cancer.gov/about-nci/organization/ccg/research/ structural-genomics/tcga). The PCPG cohort consists of data from 182 tumours.

The differential gene expression analysis compared expression (cut off value of 1.5) in the PCPG tumours with the normal controls was performed by ANOVA analysis in the online analysis tools Gene Expression Profiling Interactive Analysis (GEPIA) (21).

\section{Immunohistochemistry}

Formalin-fixed and paraffin-embedded slices of $2 \mu \mathrm{m}$ thick were stained with monoclonal mouse anti-human insulin NCL-INSULIN, clone 2D11-H5, dilution 1:100 (Leica Biosystems) and visualised by chromogen detection using UltraView DAB with amplification (Ventana, Tuscon, USA). Semi-quantification of staining (score 0-4) based on the percentage of stained cells per microscopic visual field with $20 \times$ objective: score 0 , no positive cells; score 1, 1-25\% cells; score 2, 26-50\% cells; score 3, 51-75\% cells and score $4,>75 \%$ cells. The scoring was performed twice, blinded, and with identical results.

Staining with antibodies to succinate dehydrogenase B (SDHB) was performed to assess SDH deficiency (22).

We obtained the RNA results without the knowledge of the immunohistochemistry results and vice versa.

\section{Results}

\section{Phaeochromocytomas express insulin and hybrid transcripts}

While normal adrenal tissue showed no detectable expression of INS transcripts, 17 of the 20 tumours had detectable expression (Fig. 2A). The levels varied from 11 to $83 \%$ of normal pancreatic tissue based on quantification of the amplified PCR products separated by agarose gel electrophoresis (Fig. 2A). To get a more sensitive measurement of the expression levels, we performed qRT-PCR analysis where we related the INS transcript expression levels to a dilution curve of pancreatic cDNA. The relative order of high to low expression samples did not change substantially, but with the more sensitive method, we detected the expression of insulin in two additional samples, samples 6 and 11 (Fig. 2B), giving detectable expression of INS transcript in 19 of 20 tumours.

As the INS gene is located in the upstream of IGF2, we also amplified the hybrid INS-IGF2 transcript 2 (Fig. 3). An INS-IGF2 transcript was found in 19 of the 20 tumours. The PCR reaction for INS-IGF2 transcript needed four more cycles to produce a visible band on the gel, indicating lower levels of INS-IGF2 than INS transcripts. There was no expression of INS-IGF2 transcript 2 in normal adrenal and pancreatic tissue. Hence, of the 20 phaeochromocytomas, 19 expressed the INS transcript and the hybrid INS-IGF2
This work is licensed under a Creative Commons Attribution 4.0 International License. ded from Bioscientifica.com at 04/26/2023 09:30:10AM 
A

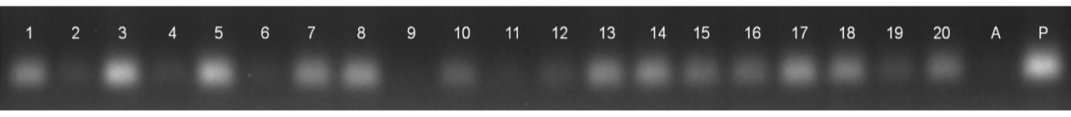

B

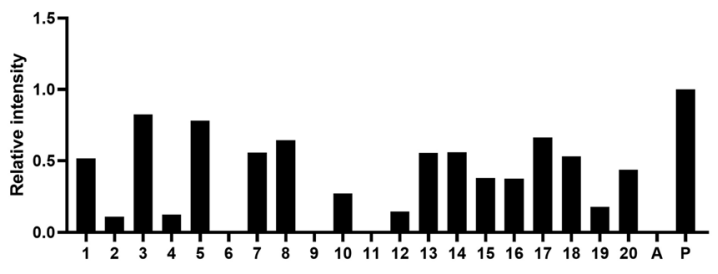

C

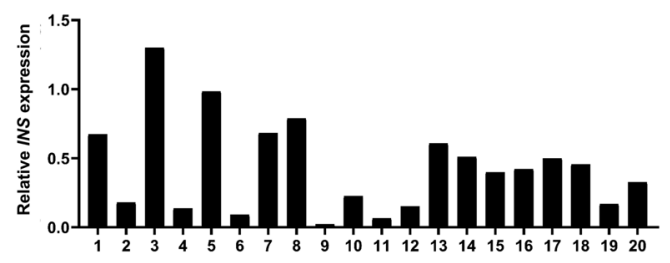

transcript 2. Their degree of expression of insulin and hybrid transcripts corresponded closely, indicating transcriptional activation of the whole region around the insulin gene.

\section{Phaeochromocytomas with different degrees of anti-insulin antibody staining}

We used immunohistochemistry to verify whether the transcripts were translated into the corresponding polypeptides. Staining with anti-insulin antibodies was mostly at a low level (score 1, twelve tumours). Four positive tumours showed a higher level of staining (score 2 , one tumour; score 3, two tumours; score 4, one tumour); representative examples in Fig. 4B, C, D and E. Only four tumours showed no positive staining.

The distribution of positive cells seems to be mostly scattered (Fig. 4B, C, D and E). However, in one sample, there was an expanding clone of strongly positive cells (Fig. 4F), and in some other samples, we found clusters of positive cells (Fig. 4G). The intracellular-stained granules in positive cells (Fig. 4G) were similar to insulin granules

\section{Figure 2}

Phaeochromocytomas express insulin transcripts. (A) Agarose gel showing the insulin PCR product after 30 cycles of PCR starting with the equivalent of 4 ng RNA. Of the 20 phaeochromocytoma samples tested (lanes 1-20), 17 show a band indicating amplification of INS transcripts. Adrenal gland (lane a) and pancreas (lane p) were used as a negative and positive control, respectively. (B) The relative quantification of signal intensity in the bands in (A) is shown in the bar diagram. The pancreas control was set to 1.0. (C) INS expression analysed with qRT-PCR. Total RNA from pancreatic tissue was reverse transcribed to cDNA and serially diluted to form a reference curve. The equivalent of $4 \mathrm{ng}$ total RNA from the phaeochromocytoma sample was used, and the resulting threshold cycle was related to the pancreatic cDNA dilution curve. With this more sensitive method, two more tumours (6 and 11) showed expression of INS transcript.

in $\beta$-cells. We found no staining of control tissues from normal liver, colon, lymph node, adrenal cortex and medulla (not shown), and exocrine pancreas (Fig. 4H).

These results show that of the 20 phaeochromocytomas 16 stained positively with anti-insulin antibodies, indicating translation of the transcripts into polypeptides. The clonal distribution indicates that different parts of a tumour show different transcriptional activation leading to different INS and INS-IGF2 expression and corresponding polypeptide synthesis. This is in line with the established concept of tumour heterogeneity.

\section{Expression of INS and INS-IGF2 transcripts in phaeochromocytoma tumours validated in TCGA}

To validate the transcription results in a larger cohort, INS and INS-IGF2 expressions were evaluated in TCGA cohort of phaeochromocytomas and paragangliomas. The analysis showed a significant difference $(P=0.01)$ in the expression of INS in the tumours compared to the normal adrenal gland (Fig. 5A). There was also an increase of INS-IGF2 in tumours compared to normal tissue (Fig. 5B). Similar to

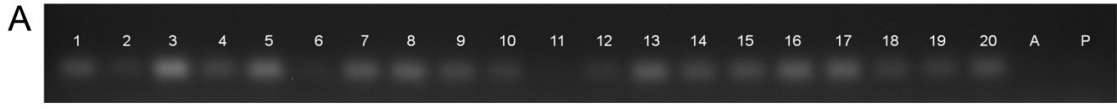

B

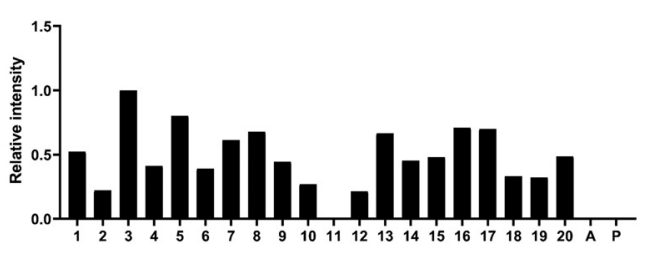

Figure 3

Phaeochromocytoma expresses INS-IGF2 transcript 2. (A) Agarose gel showing the INS-IGS2 transcript 2 PCR product of the expected size. Adrenal gland (lane a) and pancreas (lane p) were included as controls. (B) The relative quantification of signal intensity in the bands in (A) is shown in the bar diagram. The highest expressed sample was set as 1.0. The results correlate with the INS expression shown in Fig. 2 (Spearman, $r=0.80, P<0.002$ ). https://ec.bioscientifica.com https://doi.org/10.1530/EC-21-0269 (c) 2021 The authors Published by Bioscientifica Ltd

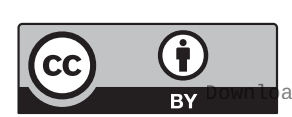

This work is licensed under a Creative Commons Attribution 4.0 International License. 

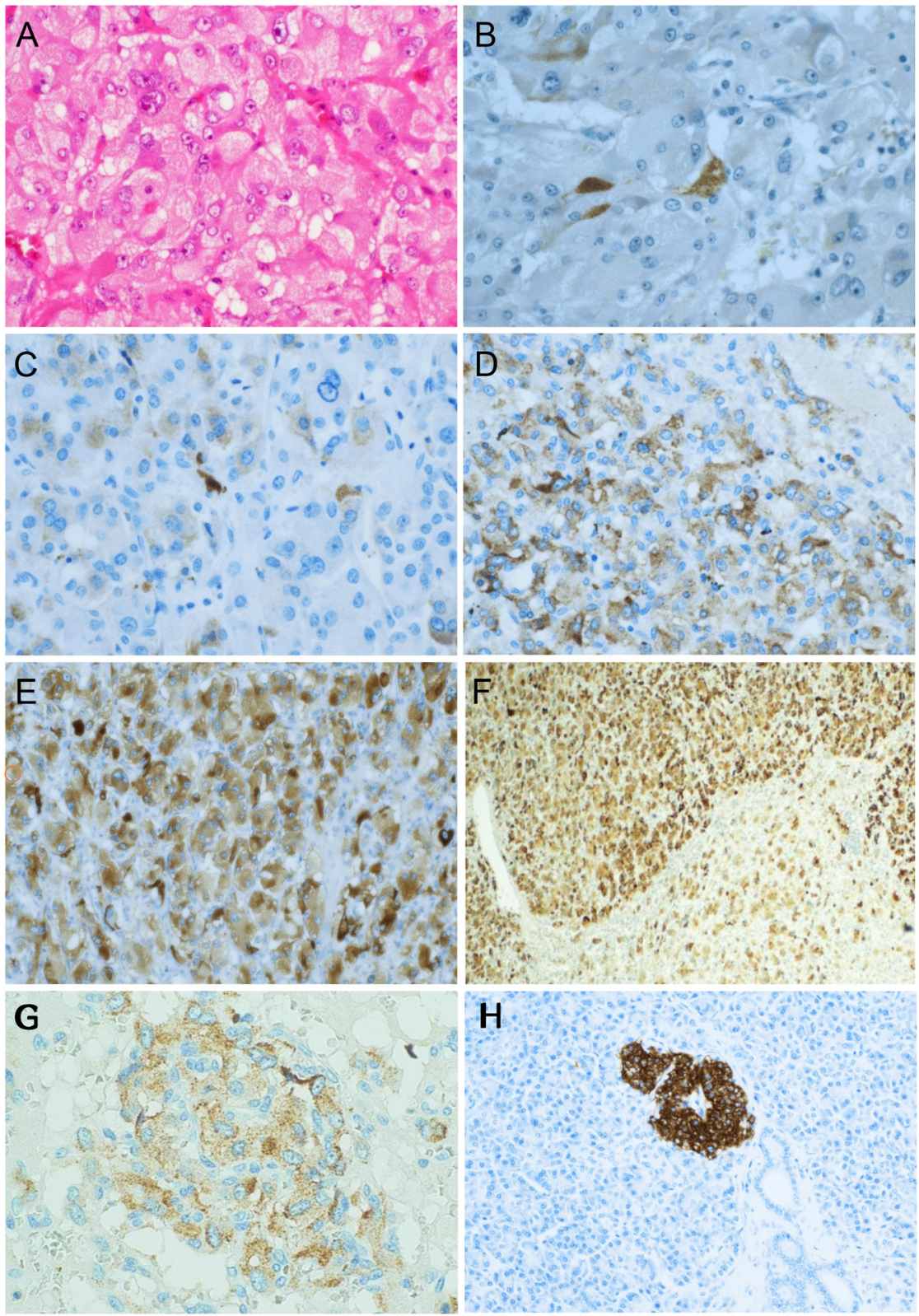

\begin{abstract}
Figure 4
Phaeochromocytomas with different degrees of anti-insulin antibody staining. (A) Standard haematoxylin-eosin staining of phaeochromocytoma. (B, C, D and E) Representative images of degree of positive staining, score 1-4: (B) score 1, 0-25\% positive cells, (C) score 2, 26-50\% positive cells, (D) score 3, $51-75 \%$ positives cells, (E) score $4,>75 \%$ positive cells. (F) Large clone (upper part) with heavily stained cells (score 4). (G) Cluster of stained cells, indicating a small clonal distribution of positive cells. $(H)$ Normal pancreas with stained $\beta$-cells (positive control) surrounded by unstained exocrine cells (negative control).
\end{abstract}

our results, the INS-IGF2 expression levels are lower than the INS expression levels. The degree of expression of the two transcripts correlates positively (Fig. 5C). Thus, the transcription data obtained from TCGA corroborate the results from our cohort.

In conclusion, activation of expression from the insulin locus is common in phaeochromocytomas. This opens the possibility that the production of insulin and the hybrid polypeptide translated from INS-IGF2 transcript in the tumours may contribute both to autocrine tumour growth effects and the glucose imbalances seen in these patients.

\section{Discussion}

We present evidence that most phaeochromocytomas contain cells that express INS transcript and INS-IGF2 transcript 2. Staining with anti-insulin antibodies supports that the transcripts are translated to polypeptides. Our findings add to the previous knowledge about the biology of these tumours and their ectopic hormone production. This opens the possibilities that the overexpression may cause or contribute both to autocrine tumour growth effects and the two types of glucose imbalance seen in patients with a phaeochromocytoma. Our cohort of https://ec.bioscientifica.com

https://doi.org/10.1530/EC-21-0269 (c) 2021 The authors Published by Bioscientifica Ltd

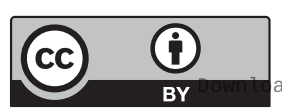

This work is licensed under a Creative Commons Attribution 4.0 International License. ded from Bioscientifica.com at 04/26/2023 09:30:10AM 
A

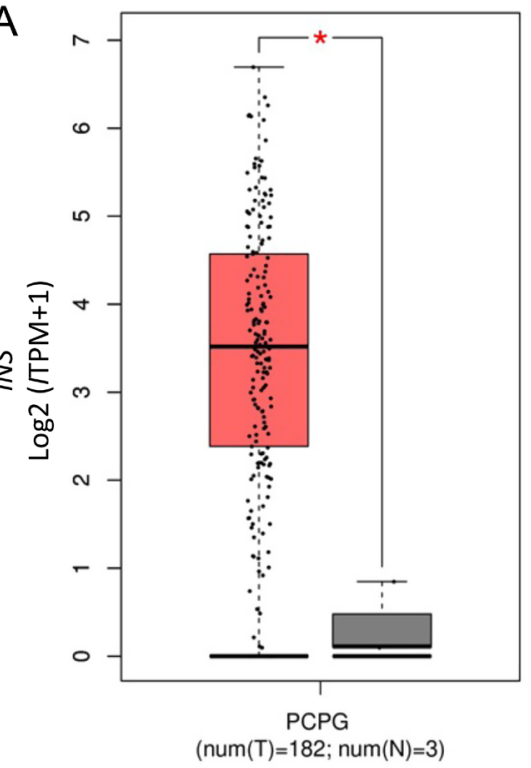

B

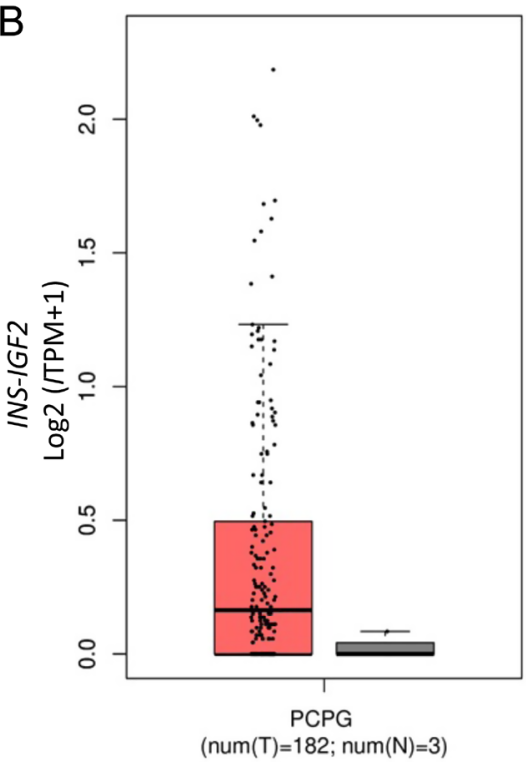

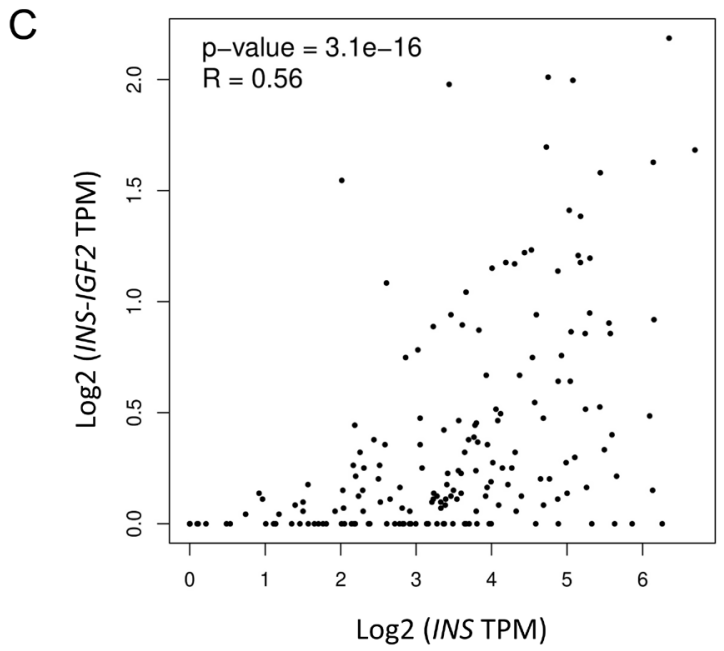

\section{Figure 5}

INS and INS-IGF2 expression in phaeochromocytomas and paragangliomas (PCPG) (A). Expression of INS transcript is significantly elevated in PCPG (red) compared to normal tissue (grey) in the TCGA dataset after ANOVA analysis with a cut off value of 1.5 $(P=0.01)$. The expression data are first $\log _{2}(T P M+1)$ transformed for differential analysis and the $\log _{2} \mathrm{FC}$ is defined as median (tumour) median (normal). Genes with higher $\left|\log _{2} \mathrm{FC}\right|$ values and lower q values than pre-set thresholds are considered differentially expressed genes (B). Expression of INS-IGF2 transcript analysed as in (A and C). Spearman correlation analysis of INS and INS-IGF2 expression. The data corroborate our findings in the 20 phaeochromocytomas. patients, recruited unselectively, constitutes a typical cohort, with two germline predisposing mutations. Other clinical features, presented in Supplementary Table 1, are also as expected in an unselected cohort.

In the fully developed body, only $\beta$-cells of the pancreas express insulin on both transcriptional and polypeptide levels. Our results of INS transcript levels close to the endogenous pancreatic levels, and the anti-insulin staining with an intracellular granular morphology (Fig. 4) similar to insulin-containing granule in $\beta$-cells in the pancreas, is, therefore, unexpected.

What could give phaeochromocytoma cells the ability to express insulin? Chromaffin cells and pancreatic $\beta$-cells are not closely related developmentally, as they come from neuronal (23) and epithelial (24) origin, respectively. However, data from studies of $\beta$-cell differentiation suggest that the developmental distance may be relatively short.
First, the whole genomic area around the INS gene (from before the beginning of the INS gene and well into the IGF2 gene) has open chromatin conformation (25), reflecting a permissive state as the first requirement for transcription. Secondly, during differentiation, $\beta$-cells acquire a methylation pattern more similar to neuronal cells than pancreatic acinar cells (24). This is interesting, as most phaeochromocytoma tumours show signs of tumour-specific changes in methylation status (26). Thirdly, demethylation of the insulin promotor, rendering it active, happens late in $\beta$-cell differentiation, and already before the activation of the promotor, low levels of INS transcripts can be detected (27). These three points support that low-level expression from the open chromatin in this region is possible without a fully active promotor.

Several lines of evidence further support the possibility of insulin expression in phaeochromocytomas. 
The IGF2 gene is localised in a region that undergoes classical maternal-paternal imprinting. Overexpression of IGF2 transcript is common in phaeochromocytomas, and mechanisms found so far are tumour- specific genomic changes in copy number, uni-parental disomy, and methylation (19). Amplifications resulting in several copies of the whole INS-to-IGF2 locus would give more templates also for insulin transcription. The uni-parental disomy, where the mother's imprinted/closed copy of IGF2 has been exchanged to a second copy of the father's actively transcribing copy, would also increase the possibility of transcription from the INS-to-IGF2 locus. Lastly, as touched upon earlier, the methylation changes leading to active IGF2 promotors may spill over to the closely located INS gene leading to its activation. Thus, there are several possible mechanisms by which genomic changes activating transcription from the IGF2 gene also could increase the expression of the INS gene in phaeochromocytoma.

Expression of INS-IGF2 is not common in normal adult tissue (28). In tumours, it has been found in nonsmall-cell lung cancer (29) and insulinomas (30). We find a high degree of correspondence between the expression of INS and INS-IGF2 transcripts, which is expected as they are transcribed from the same promotor (28). The need for four more cycles to detect the INS-IGF2 transcript suggests different expression levels, which is supported by the TCGA data showing about a 60 -fold difference in expression (Fig. $5 \mathrm{~A}$ and $\mathrm{B})$.

Kamio et al. (3) already in 1991 found that five of seven phaeochromocytomas stained positively with antiinsulin antibodies. We now confirm their finding in a larger study, where 16 of 20 tumours stained positively for insulin. In addition, we show overexpression of the INS and INS-IGF2 transcripts, and the 182 tumours in the TCGA cohort corroborate this finding, suggesting a common phenomenon.

The anti-insulin staining strongly suggests that insulin is produced by these tumours.

In addition, the INS-IGF2 transcript 2 encodes a 200 amino acid protein starting with the preproinsulin signal peptide, the insulin $B$ chain, and the first eight amino acids in the proinsulin C-peptide (28). If the B chain of INS-IGF2 polypeptide retains the same helical configuration as in insulin, it may contain epitopes present on insulin and thereby binding the same antibody. Supporting evidence comes from the finding that anti-insulin autoantibodies from patients with diabetes type 1 recognise epitopes on the B-chain part of the peptide translated from the INS-IGF2 transcript 2 (31). Thus, both insulin and the hybrid polypeptide may stain with the anti-insulin antibody.

The expression analyses and the immunostaining show that the expression levels vary substantially between the phaeochromocytomas. The clonal expansion in one sample and the clusters of positive cells in some others indicate a potential for further clonal expansion revealing variations also within tumours. Such tumour heterogeneity is well known in both cancers and benign tumours, including phaeochromocytomas (32). Another example is aldosterone-producing tumours from the adrenal cortex (33) showing clonal distributions very similar to what we find in tumours from the medulla. Therefore, the few negative tumours in our cohort may express INS and INSIGF2 transcripts and corresponding polypeptides in other areas than we examined.

We found no correlation between the degree of immunostaining and the expression of the transcripts. Several mechanisms could explain this lack of correlation. Differences in synthesis and modulation of a protein's half-life are possible mechanisms (34). For example, it has been reported that INS transcript 1 gives more efficient translation into protein than transcripts 2-4 (35). Based on the granules we see in the insulin staining, another possible way to change the relationship between transcripts and polypeptides is the secretion kinetics of the final polypeptide product. Rapid secretion would lead to small amounts present in the cell whereas cells without secretion would retain products inside the cells and, therefore, stain more strongly.

The activation of a wider region around the insulin gene may have possible autocrine stimulatory growth effects in phaeochromocytomas. They overexpress IGF-2 and its receptor (20) and the IGF-1 receptor (36), and the overexpression is most pronounced in malignant tumours (37). Our finding of overexpression of insulin may also induce autocrine growth stimulation. This is, however, less likely, because highly supraphysiological insulin concentrations are required to induce growth (38).

Phaeochromocytomas induce two types of glucose imbalances, hyperglycaemia and hypoglycaemic attacks, both occurring on top of the typical phaeochromocytoma symptoms and signs. Hyperglycaemia is common and is probably caused by two effects of catecholamines, namely increased insulin resistance and inhibition of insulin secretion from beta cells (14). Hypoglycaemic attacks are rare, only a few cases have been reported $(15,16,17,18)$ and the mechanism is not known. It has been postulated (16) that catecholamine induced $\beta$-adrenoceptor- mediated release of insulin from pancreatic $\beta$-cells may override

This work is licensed under a Creative Commons Attribution 4.0 International License. ded from Bioscientifica.com at 04/26/2023 09:30:10AM 
the prevailing $\alpha$-adrenoceptor mediated inhibition of release and the insulin resistance seen in most phaeochromocytoma patients (14). However, no evidence for this overriding mechanism is presented, and it seems unlikely that in just a few rare patients the overwhelming hyperglycaemic catecholamine effects should be switched to the opposite. Empty glucose stores in the liver have also been suggested to contribute (16). However, other phaeochromocytoma patients experience recurrent postprandial reactive hypoglycaemic attacks without any malnutrition $(17,18)$.

It is of considerable interest that our findings suggest new contributing mechanisms for both types of glucose imbalances. Obviously, hypersecretion of insulin could cause hypoglycaemic attacks. However, only very few patients suffer from hypoglycaemia and most of our phaeochromocytomas stain positively. Therefore, only tumours with heavy staining and clonal expansion of such cells may contain sufficient amounts of insulin. In addition, to cause hypoglycaemia, the normal control that stops insulin secretion from $\beta$-cells when blood glucose is low must be defective. Generally, tumours with ectopic hormone production often lack a normal regulatory mechanism of hormone secretion (39). This is also shown for insulin-producing tumours causing hypoglycaemia $(10,35)$. Therefore, if a phaeochromocytoma produces much insulin, from the whole tumour or a local clone, and the normal regulatory brake on secretion of insulin to the blood is defect, the tumour could cause hypoglycaemia. Normal $\beta$-cells constitute only about $2 \%$ of pancreatic cells $(40,41)$ so a phaeochromocytoma of around $5 \mathrm{~cm}$ would contain a sufficient number of insulin-producing cells.

The few cases that reported reactive hypoglycaemia in phaeochromocytoma suggest that these tumours may have a trigger for insulin secretion. In the pancreas, one of many triggers for insulin secretion is the stimulation of glucagonlike peptide 1 receptors (GLP1R). GLP1R expression/ protein has been found on phaeochromocytoma cells (42) and tumours (43), but whether they function normally or if they are expressed on cells positive for anti-insulin staining is not known.

Our findings may also suggest a contributing mechanism for the more common hyperglycaemia seen in phaeochromocytoma patients. The INS-IGF2 polypeptide, if secreted, may block insulin receptors, causing insulin resistance with hyperglycaemia. Normally, insulin stimulates its receptor by binding to two different sites on the receptor. The major site binds the insulin B-chain
(44). The hybrid contains the B-chain. If this B-chain part retains the same helical configuration as in insulin, the hybrid could bind to only one of the two sites, and, therefore, block the receptor.

In sum, our data suggest possible mechanisms that may contribute to dysregulated glucose metabolism in phaeochromocytoma that can be addressed in future studies. First, it should be demonstrated whether the anti-insulin staining granule structures we see are fully functional with the secretion of the polypeptide products or whether secretion requires additional triggers. One interesting question that remains to be explored is to define the mechanism(s) explaining the few cases of reactive hypoglycaemia reported in the literature given that insulin is commonly expressed in tumours, but hypoglycaemia cases are rare. As alluded to above, it remains to be defined whether the hybrid polypeptide binds to the antibodies and may compete with insulin for insulin-receptor binding and thereby contribute to hyperglycaemia. Detailed biochemical studies of receptor-binding kinetics may elucidate this point. The clonal expansions imply that heterogeneity within a tumour must be considered. Finally, but perhaps most importantly, future studies must be performed in order to correlate our findings with clinical and genetic aspects on a larger cohort of phaeochromocytoma patients.

\section{Conclusion}

Most phaeochromocytomas contain cells that overexpress INS and INS-IGF2 transcripts. Most tumours also display heterogeneous expression of polypeptides immunoreactive to monoclonal anti-insulin antibodies. Clinically this may relate to both hyperglycaemia and hypoglycaemic attacks seen in patients with phaeochromocytoma as well as autocrine tumour growth.

\section{Supplementary materials}

This is linked to the online version of the paper at https://doi.org/10.1530/ EC-21-0269.

\section{Declaration of interest}

The authors declare that there is no conflict of interest that could be perceived as prejudicing the impartiality of the research reported.

\section{Funding}

The study was supported by South-Eastern Regional Infrastructure for Clinical and Translational Research (SERIT) grant number 276984.

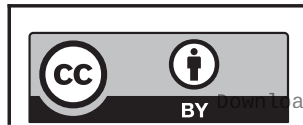

This work is licensed under a Creative Commons Attribution 4.0 International License. ded from Bioscientifica.com at 04/26/2023 09:30:10AM 


\section{References}

1 Dimitriadis GK, Angelousi A, Weickert MO, Randeva HS, Kaltsas G \& Grossman A. Paraneoplastic endocrine syndromes. Endocrine-Related Cancer 201724 R173-R190. (https://doi.org/10.1530/ERC-17-0036)

2 Ilias I, Torpy DJ, Pacak K, Mullen N, Wesley RA \& Nieman LK. Cushing's syndrome due to ectopic corticotropin secretion: twenty years' experience at the National Institutes of Health. Journal of Clinical Endocrinology and Metabolism 200590 4955-4962. (https:// doi.org/10.1210/jc.2004-2527)

3 Kamio T, Shigematsu K, Kawai K \& Tsuchiyama H. Immunoreactivity and receptor expression of insulinlike growth factor I and insulin in human adrenal tumors. An immunohistochemical study of 94 cases. American Journal of Pathology 1991138 83-91.

4 Stagno PA, Petras RE \& Hart WR. Strumal carcinoids of the ovary. An immunohistologic and ultrastructural study. Archives of Pathology and Laboratory Medicine 1987111 440-446.

5 Leach SD, LaMorte AI, True LD, Flynn SD, Schwartz PE, Cahow CE \& Kinder BK. Aberrant hormone production from ovarian neoplasms: strategies for diagnosis and therapy. World Journal of Surgery 199014 335-341. (https://doi.org/10.1007/BF01658520)

6 Ashton MA. Strumal carcinoid of the ovary associated with hyperinsulinaemic hypoglycaemia and cutaneous melanosis. Histopathology 199527 463-467. (https://doi. org/10.1111/j.1365-2559.1995.tb00311.x)

7 Morken NH, Majak B \& Kahn JA. Insulin producing primary ovarian carcinoid tumor. Acta Obstetricia et Gynecologica Scandinavica $2007 \mathbf{8 6}$ 500-501. (https://doi.org/10.1080/00016340600613477)

8 Seckl MJ, Mulholland PJ, Bishop AE, Teale JD, Hales CN, Glaser M, Watkins S \& Seckl JR. Hypoglycemia due to an insulin-secreting smallcell carcinoma of the cervix. New England Journal of Medicine 1999341 733-736. (https://doi.org/10.1056/NEJM199909023411004)

9 Shames JM, Dhurandhar NR \& Blackard WG. Insulin-secreting bronchial carcinoid tumor with widespread metastases. American Journal of Medicine 196844 632-637. (https://doi.org/10.1016/00029343(68)90065-x)

10 Battocchio M, Zatelli MC, Chiarelli S, Trento M, Ambrosio MR, Pasquali C, De Carlo E, Dassie F, Mioni R, Rebellato A, et al. Ovarian tumors secreting insulin. Endocrine 201549 611-619. (https://doi. org/10.1007/s12020-015-0605-y)

11 Morgello S, Schwartz E, Horwith M, King ME, Gorden P \& Alonso DR. Ectopic insulin production by a primary ovarian carcinoid. Cancer 198861 800-805. (https://doi.org/10.1002/10970142(19880215)61:4<800::aid-cncr2820610426>3.0.co;2-3)

12 Ramkumar S, Dhingra A, Jyotsna V, Ganie MA, Das CJ, Seth A, Sharma MC \& Bal CS. Ectopic insulin secreting neuroendocrine tumor of kidney with recurrent hypoglycemia: a diagnostic dilemma. BMC Endocrine Disorders 201414 36. (https://doi.org/10.1186/14726823-14-36)

13 Uysal M, Temiz S, Gul N, Yarman S, Tanakol R \& Kapran Y. Hypoglycemia due to ectopic release of insulin from a paraganglioma. Hormone Research 200767 292-295. (https://doi. org/10.1159/000099291)

14 Erlic Z \& Beuschlein F. Metabolic alterations in patients with pheochromocytoma. Experimental and Clinical Endocrinology and Diabetes 2019127 129-136. (https://doi.org/10.1055/a-0649-0960)

15 Abdulhadi B, Anastasopoulou C \& Lekprasert P. Tumor-induced hypoglycemia: an unusual case report and review of literature. AACE Clinical Case Reports 20217 80-83. (https://doi.org/10.1016/j. aace.2020.11.002)

16 Frankton S, Baithun S, Husain E, Davis K \& Grossman AB. Phaeochromocytoma crisis presenting with profound hypoglycaemia and subsequent hypertension. Hormones 20098 65-70. (https://doi. org/10.14310/horm.2002.1224)
17 Følling I, Olsen AL, Nermoen I \& Thorsby PM. Phaeochromocytoma and hypoglycaemic fits: a case report. Endocrine Abstracts 201537 EP1156. (https://doi.org/10.1530/endoabs.37.EP1156)

18 Thonangi RP, Bhardwaj M \& Kulshreshtha B. A case report of reactive hypoglycemia in a patient with pheochromocytoma and it's review of literature. Indian Journal of Endocrinology and Metabolism 201418 234-237. (https://doi.org/10.4103/2230-8210.129120)

19 Nielsen HM, How-Kit A, Guerin C, Castinetti F, Vollan HK, De Micco C, Daunay A, Taieb D, Van Loo P, Besse C, et al. Copy number variations alter methylation and parallel IGF2 overexpression in adrenal tumors. Endocrine-Related Cancer 201522 953-967. (https://doi.org/10.1530/ ERC-15-0086)

20 Gelato MC \& Vassalotti J. Insulin-like growth factor-II: possible local growth factor in pheochromocytoma. Journal of Clinical Endocrinology and Metabolism 199071 1168-1174. (https://doi.org/10.1210/jcem-715-1168)

21 Tang Z, Li C, Kang B, Gao G, Li C \& Zhang Z. GEPIA: a web server for cancer and normal gene expression profiling and interactive analyses. Nucleic Acids Research 201745 W98-W102. (https://doi.org/10.1093/ nar/gkx247)

22 Gill AJ. Succinate dehydrogenase (SDH)-deficient neoplasia. Histopathology 201872 106-116. (https://doi.org/10.1111/his.13277)

23 Aunis D. Exocytosis in chromaffin cells of the adrenal medulla. International Review of Cytology 1998181 213-320. (https://doi. org/10.1016/s0074-7696(08)60419-2)

24 Bramswig NC \& Kaestner KH. Organogenesis and functional genomics of the endocrine pancreas. Cellular and Molecular Life Sciences 201269 2109-2123. (https://doi.org/10.1007/s00018-011-0915-z)

25 Kuroda A, Rauch TA, Todorov I, Ku HT, Al-Abdullah IH, Kandeel F, Mullen Y, Pfeifer GP \& Ferreri K. Insulin gene expression is regulated by DNA methylation. PLoS ONE 20094 e6953. (https://doi. org/10.1371/journal.pone.0006953)

26 Castro-Vega LJ, Lepoutre-Lussey C, Gimenez-Roqueplo AP \& Favier J. Rethinking pheochromocytomas and paragangliomas from a genomic perspective. Oncogene 201635 1080-1089. (https://doi.org/10.1038/ onc.2015.172)

27 Ku HT, Chai J, Kim YJ, White P, Purohit-Ghelani S, Kaestner KH \& Bromberg JS. Insulin-expressing colonies developed from murine embryonic stem cell-derived progenitors. Diabetes 200756 921-929. (https://doi.org/10.2337/db06-0468)

28 Monk D, Sanches R, Arnaud P, Apostolidou S, Hills FA, Abu-Amero S, Murrell A, Friess H, Reik W, Stanier P, et al. Imprinting of IGF2 P0 transcript and novel alternatively spliced INS-IGF2 isoforms show differences between mouse and human. Human Molecular Genetics 200615 1259-1269. (https://doi.org/10.1093/hmg/ddl041)

29 Gao S, Lin Z, Li C, Wang Y, Yang L, Zou B, Chen J, Li J, Feng D, Song Z, et al. IncINS-IGF2 promotes cell proliferation and migration by promoting G1/s transition in lung cancer. Technology in Cancer Research and Treatment 2019181533033818823029 . (https://doi. org/10.1177/1533033818823029)

30 Johannessen LE, Panagopoulos I, Haugvik SP, Gladhaug IP, Heim S \& Micci F. Upregulation of INS-IGF2 read-through expression and identification of a novel INS-IGF2 splice variant in insulinomas. Oncology Reports 201636 2653-2662. (https://doi.org/10.3892/ or.2016.5132)

31 Kanatsuna N, Taneera J, Vaziri-Sani F, Wierup N, Larsson HE, Delli A, Skärstrand H, Balhuizen A, Bennet H, Steiner DF, et al. Autoimmunity against INS-IGF2 protein expressed in human pancreatic islets. Journal of Biological Chemistry 2013288 29013-29023. (https://doi. org/10.1074/jbc.M113.478222)

32 Crona J, Backman S, Maharjan R, Mayrhofer M, Stalberg P, Isaksson A, Hellman P \& Bjorklund P. Spatiotemporal heterogeneity characterizes the genetic landscape of pheochromocytoma and defines early events in tumorigenesis. Clinical Cancer Research 201521 4451-4460. (https:// doi.org/10.1158/1078-0432.CCR-14-2854) https://ec.bioscientifica.com https://doi.org/10.1530/EC-21-0269 (c) 2021 The authors Published by Bioscientifica Ltd

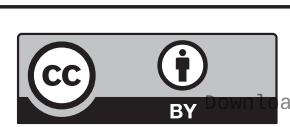

This work is licensed under a Creative Commons Attribution 4.0 International License. ded from Bioscientifica.com at 04/26/2023 09:30:10AM 
33 Dekkers T, ter Meer M, Lenders JW, Hermus AR, Schultze Kool L, Langenhuijsen JF, Nishimoto K, Ogishima T, Mukai K, Azizan EA, et al. Adrenal nodularity and somatic mutations in primary aldosteronism: one node is the culprit? Journal of Clinical Endocrinology and Metabolism 201499 E1341-E1351. (https://doi.org/10.1210/jc.20134255)

34 Liu Y, Beyer A \& Aebersold R. On the dependency of cellular protein levels on mRNA abundance. Cell 2016165 535-550. (https://doi. org/10.1016/j.cell.2016.03.014)

35 Minn AH, Kayton M, Lorang D, Hoffmann SC, Harlan DM, Libutti SK \& Shalev A. Insulinomas and expression of an insulin splice variant. Lancet 2004363 363-367. (https://doi.org/10.1016/S01406736(04)15438-X)

36 Fottner C, Minnemann T, Kalmbach S \& Weber MM. Overexpression of the insulin-like growth factor I receptor in human pheochromocytomas. Journal of Molecular Endocrinology 200636 279-287. (https://doi.org/10.1677/jme.1.01975)

37 Fernandez MC, Martin A, Venara M, Calcagno Mde L, Sanso G, Quintana S, Chemes HE, Barontini M \& Pennisi PA. Overexpression of the insulin-like growth factor 1 receptor (IGF-1R) is associated with malignancy in familial pheochromocytomas and paragangliomas. Clinical Endocrinology 201379 623-630. (https://doi.org/10.1111/ cen.12205)

38 Bedinger DH \& Adams SH. Metabolic, anabolic, and mitogenic insulin responses: a tissue-specific perspective for insulin receptor activators.
Molecular and Cellular Endocrinology 2015415 143-156. (https://doi. org/10.1016/j.mce.2015.08.013)

39 Kaltsas G, Androulakis II, de Herder WW \& Grossman AB. Paraneoplastic syndromes secondary to neuroendocrine tumours. Endocrine-Related Cancer 201017 R173-R193. (https://doi.org/10.1677/ ERC-10-0024)

40 Robertson FO. A quantitative estimation of the pancreatic islet tissue. QJM 19376 287-300. (https://doi.org/10.1093/oxfordjournals.qjmed. a068286)

41 Saisho Y, Butler AE, Manesso E, Elashoff D, Rizza RA \& Butler PC. $\beta$-Cell mass and turnover in humans: effects of obesity and aging. Diabetes Care 201336 111-117. (https://doi.org/10.2337/dc12-0421)

42 Saber-Ayad M, Zaher D, Manzoor S \& Omar H. PO-453 effect of GLP-1 on proliferation and migration in pheochromocytoma and colorectal cancer cells. ESMO Open 20183 A199-A200. (https://doi.org/10.1136/ esmoopen-2018-EACR25.474)

43 Körner M, Stöckli M, Waser B \& Reubi JC. GLP-1 receptor expression in human tumors and human normal tissues: potential for in vivo targeting. Journal of Nuclear Medicine 200748 736-743. (https://doi. org/10.2967/jnumed.106.038679)

44 Thorsøe KS, Schlein M, Steensgaard DB, Brandt J, Schluckebier G \& Naver H. Kinetic evidence for the sequential association of insulin binding sites 1 and 2 to the insulin receptor and the influence of receptor isoform. Biochemistry 201049 6234-6246. (https://doi. org/10.1021/bi1000118)

Received in final form 3 June 2021

Accepted 25 June 2021

Accepted Manuscript published online 25 June 2021

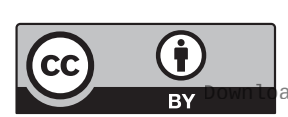

This work is licensed under a Creative Commons Attribution 4.0 International License.

ded from Bioscientifica.com at 04/26/2023 09:30:10AM 